\title{
Modern methods of motor-wheel gearboxe diagnostics of BelAZ dump trucks
}

\author{
Andrey Kudrevatykh*, Andrey Ashcheulov, and Andrey Vinidiktov \\ T. F. Gorbachev Kuzbass State Technical University, 65000, Vesennya St, 28, Kemerovo, \\ Kemerovo region, Russia
}

\begin{abstract}
The most important mining enterprise indicators are the reliability and durability of its equipment. These equipment parameters have the greatest impact not only on the mining complex efficiency, but also on the extracted minerals price, as the equipment downtime, as well as, the cost of repair works and spare parts purchase are included in the cost of coal. Thus, the main goal in improving mining production is to improve the reliability and durability of used equipment. Researches carried out in the coal company 'Kuzbassrazrezugol' showed that the largest number of mining equipment downtime, in particular of mining dump trucks, occurs due to unexpected failure of a motor-wheel gearbox. The introduction of the additional technological operation for diagnosing the actual technical condition of gearboxes in the maintenance procedure will allow monitoring the condition of the entire gearbox and, in particular, its components by an in-place repair method. This method consists of continuous or periodic measurement of the vibrations of the operating gearbox mechanisms. The analysis of the unit and its individual parts suitability is carried out on the bases of obtained measurements. This methodology usage at a mining enterprise will significantly reduce the number of equipment downtime and thereby increase its efficiency.
\end{abstract}

\section{Introduction}

Today, the open-pit mining is the lowest cost method, highly efficient and what is the most important it is the safest mining method. Of course, the open-pit mining also has its so-called drawbacks, the largest of which is the long excavators and mining dump trucks downtime. Consequently, if downtime decreases, the efficiency of mining equipment will increase significantly and it will lead to production cost decrease $[1,2,3]$.

Due to a very ineffective indicator of mining equipment reliability, the costs and expenses for repair works and spare parts purchase increase, which sometimes exceeds the amount of equipment cost in several times.

The increase in volume of transportation using highway transport is observed at many enterprises of coal industry in Kuzbass. A large quantitative increase can be observed now in the coal company 'Kuzbassrazrezugol' $[4,5,6]$. The high growth rate of the branches is because this coal company gives the greatest preference to mining equipment reliability

${ }^{*}$ Corresponding author: kav.ea@,kuzstu.ru 
increase and maintenance cost reduction. For example, the number of dump trucks at the Taldinsky Coal Mine branch has recently increased by 30 units, which corresponds to approximately $22 \%$ of the total vehicle amount. This can be explained by the traffic growth.

The increase in reliability and durability of coal mining enterprises directly affects the reduction in the number of unexpected equipment downtime $[7,8]$.

\section{Results and discussion}

When investigating the number of failures at Taldinsky Coal Mine branch, there is a tendency for a significant increase in the number of downtime of BelAZ mining dump trucks. In comparison with the previous year, the number of downtime increased by 2.3 times, which, correspondingly, led to a significant decrease in efficiency and led to the increase in the losses of cargo turnover [9, 10, 11, 12]. Having done the downtime analysis, it turned out that the largest number of downtime occurs due to the failure of the motor-wheel gearboxes, which was 9,360 operating hours, which is $3.78 \%$ of the total downtime of the vehicle fleet at the branch. This means that in order to reduce the number of unforeseen failures of mining dump trucks, it is necessary to develop and implement an additional technological operation to monitor the actual technical condition of the motor-wheel gearboxes.

Several methods stand out among the known methods for determining the actual technical state of a motor-wheel gearbox of a mining dump truck: namely, physical and chemical analysis of the used gearbox oil, the temperature method based on measuring the oil temperature, acoustic, temperature analysis using a thermal imager and vibration diagnostics.

When using the physical and chemical analysis of the used oil, oil samples were taken from a ranging gear of excavators and gearboxes of motor-wheels of mining dump trucks. The interval with which the samples were taken is equal to 50 operating hours, as the most optimal value, which allows tracking changes in metal impurities in dynamics. An example of an obtained data diagram is shown in Figure 1.

Despite the advantages of the method of oil physical and chemical analysis with the determination of the impurities percentage, it has a number of disadvantages: namely: either the enterprise must have its own chemical laboratory to assess the quality of the oil and qualified employees who can work in it must be there, or the enterprise must involve a thirdparty organization that can perform chemical analysis, which is additional expense. Also, this technique has a significant drawback during the maintenance procedure, when changing the oil in a gearbox. Since the oil is completely replaced, the impurities accumulated during operation are removed with the used oil. Therefore, it is not possible to assess the degree of rubbing surface wear of a gearbox. 


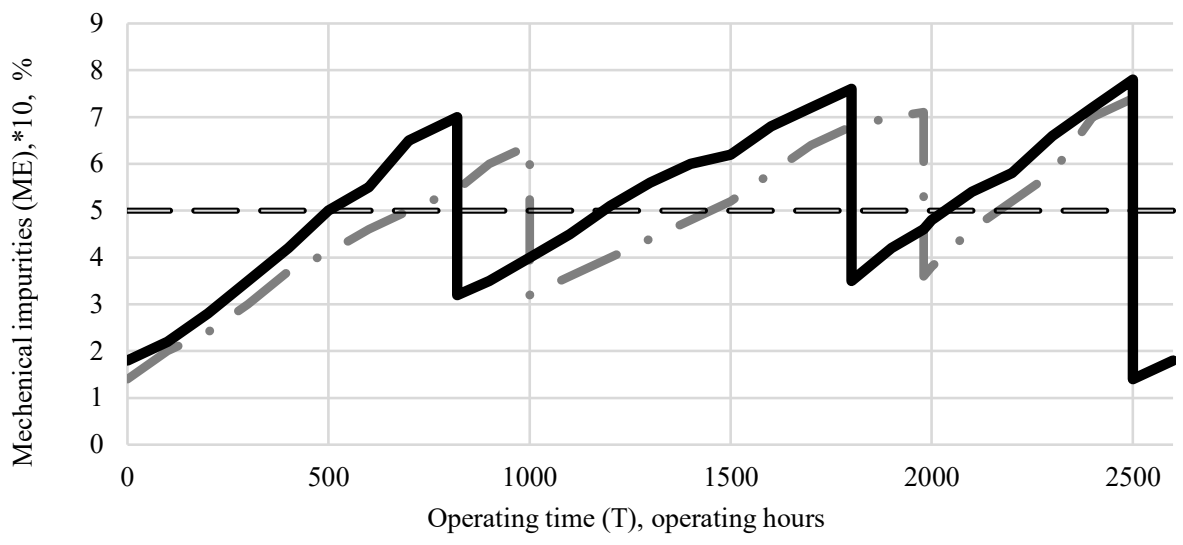

$\longrightarrow$ Dump truck Excavator $\longrightarrow$ Critical concentration

Fig. 1. The diagram of metallic impurities content in dump trucks and excavators gearboxes

The method for determining the actual technical condition of the BelAZ motor wheel gearboxes involves installing a temperature sensor in the gearbox housing, which records temperature changes (Figure 2). This method of in-place repair diagnostics allows to determine not only the degree of wear of the main gearbox mechanisms, but also to assess the influence of the atmosphere temperature. The main disadvantage of this method is that it is necessary to stop the dump truck to install the sensor, as well as, and in the way of installing this sensor, since while the gearbox housing is drilling, it is possible for large chips to enter the gearbox. It is also important that the temperature can be taken off only at one point of the gearbox. The following method of control does not have this drawback.

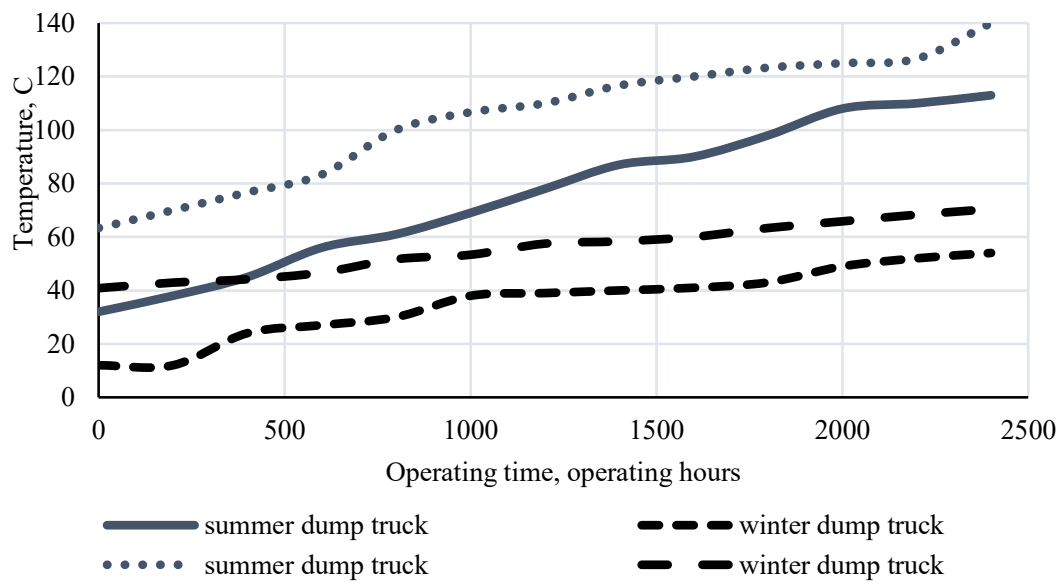

Fig. 2. Changes in oil temperature in the gearbox of a dump truck and excavator in summer and winter

In-place repair diagnostics of BelAZ motor-wheel gearboxes is based on the monitoring of gearbox temperature with the help of a thermal imager. In this case, there is no need to install any sensors on a mining dump truck, it is enough to be near it, but this is also a disadvantage, as it is necessary to go to the open-pit to take measurements, when with the previous methods it is possible to make measurements remotely. It is known that operating oil accumulates metallic impurities in it, based on which the actual technical condition of the 
gearbox can be seen; when oil is clogged with various deposits and wear products, its physical and chemical properties, including viscosity, are violated. In this regard, various particles 'stick' in the places of wear, this fact increases the friction force, and as a result, the temperature of both the oil and the entire unit increases. The main advantage of the temperature analysis is in the determination of local overheating, which makes it possible to determine a probable faulty gearbox part. However, this method is very dependent on the atmosphere temperature, and temperature indicators will vary greatly at different times of the year. Therefore, it is difficult to make a universal table for comparing the parameters of the technical condition of a gearbox.

Vibration diagnostics methods are aimed to detect and identify malfunctions of mining machines and equipment units that affect their vibration, defects in plain bearings and rolling bearings, gears that experience or generate dynamic loads.

Vibration diagnostics solves the following practical tasks of machines and equipment servicing:

- division of possible technical conditions of the unit into two subsets: serviceable and faulty;

- making a diagnosis, which consists in determining the nature and localization of one or a group of defects corresponding to the vibration state of the unit;

- possible detection of a defect at an early stage and forecasting its development in time.

According to the industry standard 20911-89, several indicators of the quality of technical diagnostics are distinguished - these are the duration, reliability, completeness of state control and the search for the place of failure. The technical condition of the gearbox, as well as of any mechanism as a whole, is determined by the state of its individual parts, thus, in order to identify the operability of the gearbox reliably, firstly, it will be necessary to select the diagnostic parameters (gearbox units and their typical defects).

One of the methods for vibration diagnostics of gearboxes, which fully meets the requirements of the industry standard 20911-89 and allows to determine both the depth and the type of defect in the gearbox, is the analysis of the direct signal spectrum (Fig. 3 ).

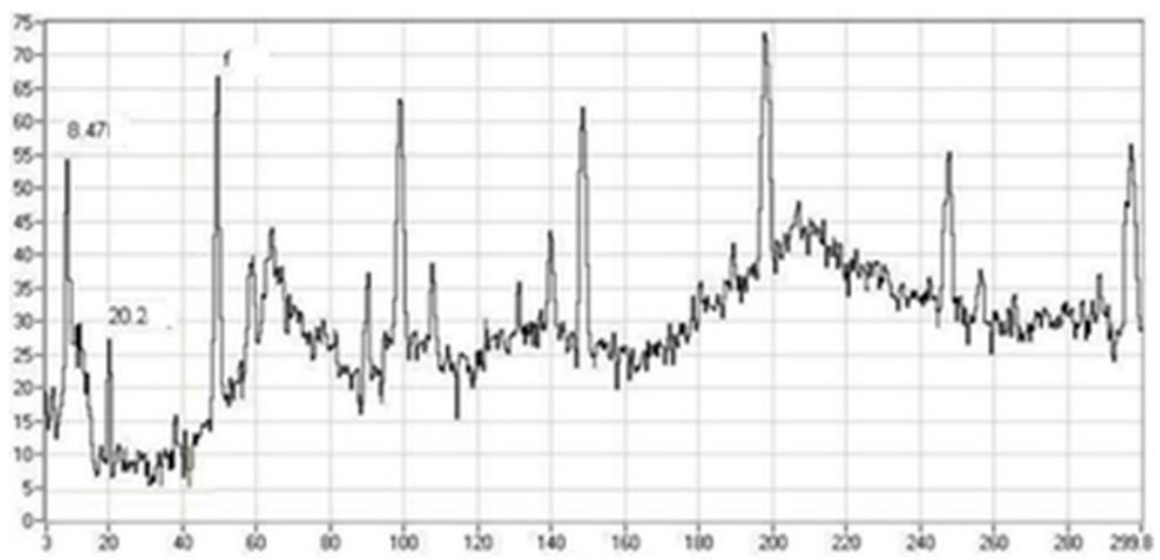

Fig. 3. Direct signal spectrum analysis

Vibration diagnostics of gearboxes using the direct signal spectrum method is based on determining the frequency of vibration jumps. The entire frequency range is divided into many narrow-band spectra, which are subsequently analysed by a specialized device. Each defect in a gearbox (gear pair, bearings or shaft) manifests itself at a certain frequency, thus, knowing the frequency at which vibration bursts occur, one can determine the reason that caused them. 
The direct spectrum method makes it possible to obtain information about the state of each kinematic unit of the gearbox separately. The defect depth is determined by the amplitude of the burst [5].

Another way to determine the defects of the gearbox (the determination of defects in its bearings) is the analysis of the spectrum envelope.

Efector Octavis from ifm is a modern stationary system of bearings vibration diagnostics that can detect vibration by direct spectrum and the spectrum envelope. The system includes the VSE series controller and the VSA and VSP series vibration sensors. According to the algorithms put in it, the signals from the sensors installed in the operating mechanism are processed in the controller.

The system is capable to diagnose a large number of different defects, such as:

- Breakages of the driving and (or) driven shaft;

- Imbalance of the driving / driven gear;

- Defective drive and (or) driven gear teeth;

- Defects in engagement or lubrication in engagement;

- Defects in the bearings design;

- Excessive or insufficient bearing lubrication.

\section{Conclusion}

Reliability and durability are important aspects of mining equipment operation and dump trucks in particular. Unplanned downtime of open-pit equipment will decrease with increase of reliability and durability. If to introduce such technological operation as the in-place repair method of diagnostics into the list of maintenance, it will significantly reduce losses in the volume of mined rock mass and reduce the cost of coal; and it will effect positively on the enterprise economic growth. It is possible to use any of the listed methods for determining the actual technical state of the gearbox of the motor-wheel of BelAZ mining dump trucks; the choice depends only on the operating conditions, as well as on the capabilities of an enterprise.

\section{References}

1. S. Zhironkin, G. Barysheva, A. Khoreshok, M. Tyulenev, M. Hellmer, Innovative Technologies in Engineering, 12127 (2016)

2. M Dadonov, A. Kulpin, O. Ostanin and E. Suleimenov, E3S Web of Conferences. International Innovative Mining Symposium, 105, 03009 (2019)

3. A. Kosolapov and S. Krysin, E3S Web of Conferences, 21, 03012 (2017)

4. A. Efremenkov, A. Khoreshok, S. Zhironkin, A. Myaskov, IOP Conference Series: Earth and Environmental Science, 012009 (2017)

5. A. Kudrevatykh, A. Ashcheulov, A. Ashcheulova, IOP Conf. Series: Materials Science and Engineering, 537, 032033 (2019)

6. A. Kudrevatykh, A. Ashcheulov, A. Ashcheulova, O. Karnadud, L. Rattmann, E3S Web of Conferences, 105, 03021 (2019)

7. I. Prigogine, R. Herman, Amer. Elsevier Publ. Co. (1971)

8. D. Stenin, N. Stenina, A. Bakanov, Coal in the 21st Century: Mining, Processing and Safety, 256 (2016) 
9. D. Landheer, Additives for lubricants and operational fluids. Ostfildem: Techninshe Akademie Esslingen Druck, 1 (1986)

10. D. Stenin, A. Kulpin, E. Kultayev, E. Kulpina, V. Borovtsov, Coal in the 21 st Century: Mining, Processing and Safety, 116 (2016)

11. Q. Sunqing, D. Junxiu, Ch. Guoxu, Lubricating Science, 3, 11, 165 (1999)

12. D. Stenin, N. Stenina, E3S Web of Conferences, 23, 03002 (2017) 